\title{
Genome-wide association study of liking of physical activity in the UK Biobank
}

Yann C. Klimentidis ${ }^{1^{*}}$, Michelle Newell ${ }^{1}$, Matthijs D. van der Zee ${ }^{2,3}$, Victoria L. Bland ${ }^{4}$, Sebastian MayWilson ${ }^{5}$, Cristina Menni ${ }^{6}$, Massimo Mangino ${ }^{6,7}$, Amit Arora ${ }^{1}$, David A. Raichlen ${ }^{8}$, Gene E. Alexander 9,10,11,12, James F. Wilson ${ }^{5,13}$, Dorret I. Boomsma ${ }^{2,3}$, Jouke-Jan Hottenga ${ }^{2,3}$, Eco J.C. de Geus ${ }^{2,3}$, Nicola Pirastu $^{5^{*}}$ (1)

${ }^{1}$ Department of Epidemiology and Biostatistics, Mel and Enid Zuckerman College of Public Health, University of Arizona, Tucson, AZ, USA

${ }^{2}$ Department of Biological Psychology, Vrije Universiteit Amsterdam, The Netherlands.

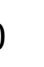

${ }^{3}$ Netherlands Twin Register, The Netherlands.

${ }^{4}$ Division of Geriatric Medicine, School of Medicine, University of Colorado Anschutz Medical Campus, Aurora, CO 80045 USA

${ }^{5}$ Centre for Global Health Research, Usher Institute, University of Edinburgh, Edinburgh, United Kingdom.

${ }^{6}$ Department of Twin Research and Genetic Epidemiology, King's College London, London SE1 7EH, UK ${ }^{7}$ NIHR Biomedical Research Centre at Guy's and St Thomas' Foundation Trust, London SE1 9RT, UK

${ }^{8}$ Human and Evolutionary Biology Section, Department of Biological Sciences, University of Southern California, CA, USA

${ }^{9}$ Department of Psychology and Psychiatry, University of Arizona, Tucson, AZ, USA.

${ }^{10}$ Neuroscience and Physiological Sciences Graduate Inter-Disciplinary Programs, University of Arizona, Tucson, AZ, USA

${ }^{11}$ Evelyn F. McKnight Brain Institute, University of Arizona, Tucson, AZ, USA

${ }^{12}$ Arizona Alzheimer's Consortium, AZ, USA 
medRxiv preprint doi: https://doi.org/10.1101/2021.10.13.21264969; this version posted October 14, 2021. The copyright holder for this preprint

(which was not certified by peer review) is the author/funder, who has granted medRxiv a license to display the preprint in perpetuity.

It is made available under a CC-BY-NC-ND 4.0 International license.

${ }^{13}$ MRC Human Genetics Unit, Institute of Genetic and Molecular Medicine, University of Edinburgh,

Western General Hospital, Crewe Road, Edinburgh, EH4 2XU, Scotland

26

* Department of Epidemiology and Biostatistics, Mel and Enid Zuckerman College of Public Health,

University of Arizona, Tucson, AZ, USA; yann@email.arizona.edu

Centre for Global Health Research, Usher Institute for Population Health Sciences and Informatics,

32 Keywords: genome-wide association study, physical activity, liking, preferences, genetic, exercise 
medRxiv preprint doi: https://doi.org/10.1101/2021.10.13.21264969; this version posted October 14, 2021. The copyright holder for this preprint (which was not certified by peer review) is the author/funder, who has granted medRxiv a license to display the preprint in perpetuity.

It is made available under a CC-BY-NC-ND 4.0 International license .

\section{ABSTRACT}

A lack of physical activity (PA) is one of the most pressing health issues facing society today. Our individual propensity for PA is partly influenced by genetic factors. Stated liking of various PA behaviors may capture additional dimensions of PA behavior that are not captured by other measures, and contribute to our understanding of the genetics of PA behavior. Here, in over 157,000 individuals from the UK Biobank, we sought to complement and extend previous findings on the genetics of PA behavior by performing genomewide association studies of self-reported liking of several PA-related behaviors plus an additional derived trait of overall PA-liking. We identified a total of 19 unique genome-wide significant loci across all traits, only four of which overlap with loci previously identified for PA behavior. The PA-liking traits were genetically correlated with self-reported $\left(\mathrm{r}_{\mathrm{g}}: 0.38-0.80\right)$ and accelerometry-derived $\left(\mathrm{r}_{\mathrm{g}}: 0.26-0.49\right) \mathrm{PA}$ measures, and with a wide range of health-related traits and dietary behaviors. Replication in the Netherlands Twin Register (NTR; $n>7,300)$ and the TwinsUK $(n>1,300)$ study revealed directionally consistent associations. Polygenic risk scores (PRS) were then trained in UKB for each PA-liking trait and for selfreported PA behavior. The PA-liking PRS significantly predicted the same liking trait in NTR. The PRS for liking of going to the gym predicted PA behavior in NTR $\left(\mathrm{r}^{2}=0.40 \%\right)$ nearly as well as the one constructed based on self-reported PA behavior $\left(r^{2}=0.42 \%\right)$. Combining the two PRS into a single model increased the $r^{2}$ to $0.59 \%$, suggesting that although these PRS correlate with each other, they are also capturing distinct dimensions of PA behavior. In conclusion, we have identified the first loci associated with PA-liking, and extended and refined our understanding of the genetic basis of PA behavior. 


\section{INTRODUCTION}

Levels of physical activity (PA) have decreased dramatically in most parts of the world over the past several hundred years, likely contributing to a major and growing chronic disease burden ${ }^{1-3}$. Physical inactivity has been compared to smoking in terms of its impact on disease burden, which ranges widely from cardiometabolic disease to mental health ${ }^{1}$. As genetic factors partly explain individual differences in PA behavior $^{4-7}$, identifying specific genetic risk factors can advance our understanding of 1) important interindividual variation, 2) relevant biological pathways, and 3) the presence, direction, and strength of causal relationships between PA behaviors and health outcomes.

Several loci have already been identified as being associated with self-reported and accelerometrymeasured levels of $\mathrm{PA}^{8,9}$. These measures may each be limited in multiple ways. For example, self-reported measures may be highly influenced by social- and health-related pressures and may not be stable over time, while accelerometer measures may only be sensitive to certain types of PA, with wear-time often limited to a single week of a person's lifetime and likely influencing behavior ${ }^{10}$. Measures of an individual's liking of PA may more accurately capture overall life-long propensity to engage in PA, and at a minimum, serve as complementary, broader, and refined measures of PA behavior.

To discover genetic loci associated with PA-related liking, we performed GWAS of five individual liking traits and one composite trait in over 157,000 UK Biobank participants, with replication of top loci in the Netherlands Twin Register (NTR) and TwinsUK studies. We then examined how these traits genetically relate to self-reported and accelerometry-measured $\mathrm{PA}^{8}$, and to a wide range of other traits and health outcomes. Finally, we examined how polygenic scores (PGS) of PA-liking derived from the UK Biobank predicted both liking and self-reported PA in the NTR study. 


\section{METHODS}

75

76

77

78

79

80

81

82

83

84

85

86

87

88

89

90

91

92

93

94

\section{UK Biobank}

The UK Biobank is a prospective cohort study of 500,000 adults (ages 37-73 at the baseline examination in 2006-2010) from the UK ${ }^{11}$. All participants provided written informed consent, and ethical approval for this study was granted. Ethical approval for the UK Biobank study was obtained by the National Information Governance Board for Health and Social Care, and the National Health Service North West Multicenter Research Ethics Committee.

\section{Physical activity liking}

In 2019, a link to a questionnaire was sent by email to UK Biobank participants to assess liking of specific foods as well as physical activities ${ }^{12}$. This online questionnaire consisted of 150 items, five of which were related to PA (going to the gym, working up a sweat, exercising with others, exercising alone, and bicycling), and assesses liking through a 9-point hedonic scale ranging from 1 for extremely dislike up to 9 for extremely like, in increments of one. The same items were asked in the two replication studies (see below).

Genetic markers

Genotypes in the UK Biobank were measured with the Affymetrix UK Biobank Axiom Array (Santa Clara, CA, USA) in $90 \%$ of participants. The remainder (10\%) were genotyped with the Affymetrix UK BiLEVE Axiom Array. Further details about imputation, principal components analysis, and QC procedures can be found elsewhere ${ }^{13}$. 
medRxiv preprint doi: https://doi.org/10.1101/2021.10.13.21264969; this version posted October 14, 2021. The copyright holder for this preprint (which was not certified by peer review) is the author/funder, who has granted medRxiv a license to display the preprint in perpetuity.

It is made available under a CC-BY-NC-ND 4.0 International license .

Replication of sentinel SNPs in Netherlands Twin Register (NTR) and TwinsUK

97

The NTR is a longitudinal register of twins and their relatives ${ }^{14}$. Between December 2014 and May 2017, participants responded to the same liking questionnaire as the one administered in the UK Biobank, including the same 5 PA-related questions ${ }^{15}$. Details regarding genotyping are provided in Supplementary Methods. Top genome-wide significant SNPs or their proxies from the UK Biobank GWASs were interrogated for each respective trait in NTR GWAS results. Since we tested $25 \mathrm{SNPs} /$ loci, a replication was deemed successful if the p-value was $<0.002$. Polygenic scores (PGS) were calculated in NTR with the LDPRED package ${ }^{16}$, based on UKB GWAS results for PA-liking and for SSOE (strenuous sports or other exercise) and other PA behavior measures ${ }^{8}$, and were tested for correlation with PA-liking phenotypes and self-reported PA behavior in NTR (see Supplementary Methods for more details).

TwinsUK is a large twin registry for the study of health that began in $1992^{17}$. The same liking questionnaire used in UK Biobank was previously used in the TwinsUK cohort ${ }^{18}$. TwinsUK genotype has been previously described in detail ${ }^{19}$. Briefly, TwinsUK samples were genotyped with a combination of two Illumina arrays (HumanHap300, HumanHap610Q). After the Genotype QC stage, the samples from the two arrays were combined and the imputations were performed using the Michigan Imputation Server ${ }^{20}$ using the 1000 Genomes Phase3 v5 reference panel.

\section{Statistical analyses}

To assess associations of PA liking with sex, age, body mass index (BMI), income, University/College degree (yes/no), and Townsend Deprivation Index, we performed linear regression after ensuring normality and homoscedasticity of residuals. In GWAS, we included only individuals of European descent. We 
considered participants as being of European descent if they were either among the genetically British as defined by UK Biobank or self-identified as "Irish", "White", or "Any other White background". We performed GWAS with fastGWA ${ }^{21}$, which implements a mixed-effect linear regression that controls for population stratification and relatedness. We included age at time of questionnaire, sex, genotyping chip,

batch, and the first 10 genetic principal components, as covariates. We used LD-score regression to assess test score inflation, SNP-based heritability, and to assess genetic correlations among PA-liking traits and previously reported PA traits ${ }^{22}$. To obtain a measure of overall PA liking, we also derived a GWAS of the

124 first principal component (PC) derived through the genetically-independent phenotype (GIP) method ${ }^{23,24}$ and starting from the genetic correlation matrix to derive the loadings of each trait on each GIP. Independent significant loci were identified as those with $\mathrm{p}<5 \times 10^{-8}$ with $\mathrm{r}^{2}<0.1$, and $>250 \mathrm{~kb}$ distance. The online LDHUB platform ${ }^{25}$ was used to examine genetic correlations of the five individual liking traits and the overall PA-liking (GIP1) trait with a wide range of traits and diseases ( $~ 800$ phenotypes). We used stratified

LD score regression to identify cell type-specific enrichment of heritability ${ }^{26}$ from the overall PA-liking (GIP1) GWAS.

\section{RESULTS}

Descriptive statistics of UKB, NTR, and TwinsUK samples and mean PA-liking levels are shown in

Supplementary Table 1. Mean score of liking was highest for exercising with others in the two UK

samples, and highest for bicycling in NTR. It was lowest for going to the gym in all three samples. In the UK

Biobank, PA liking was negatively correlated with age, and was higher in males (except for exercising with

others). We observed generally positive correlations of PA-liking traits with education and income, and 
medRxiv preprint doi: https://doi.org/10.1101/2021.10.13.21264969; this version posted October 14, 2021. The copyright holder for this preprint (which was not certified by peer review) is the author/funder, who has granted medRxiv a license to display the preprint in perpetuity.

It is made available under a CC-BY-NC-ND 4.0 International license .

negative correlations with Townsend Deprivation Index (e.g. exercising with others), such that less deprivation was associated with more PA-liking (Supplementary Table 2).

\section{Genome-wide association study}

Data from up to 158,189 UK Biobank participants (mean age=66.8; 57\% female) were analyzed for

GWAS. SNP-based trait heritabilities varied from 0.054 (0.004) for going to the gym, up to 0.075 (0.004) for bicycling. SNP heritability for overall PA-liking (GIP1) was 0.089 (0.004) (Supplementary Table 3). We did not observe evidence of genomic inflation beyond that explained by polygenic signal according to LDscore regression estimates (Supplementary Table 2). Between 2 and 6 genome-wide significant loci were identified for each individual liking trait, and 8 loci for overall PA-liking (GIP1), for a total of 25 SNP-trait associations in 19 loci (Figure 1 and Table 1). We did not observe a large degree of overlap of top loci across the five different liking traits. Only two loci (CADM2 and the locus on chromosome 11) were significantly associated with more than one trait. Sentinel SNPs were also associated with other traits such as with bone mineral density, body size and body composition, educational attainment, respiratory traits, psychiatric traits, as well as other PA-related traits such as usual walking pace and time watching television

(Supplementary spreadsheet). Cell-type enrichment analysis via stratified LD score regression identified the nucleus accumbens, hippocampus, caudate, frontal cortex, and amygdala cell types (Supplementary

Table 4).

In the NTR replication, we found directional consistency for 19 out of 25 SNPs, including 6 out of 8 PA-liking (GIP1) SNPs (Table 1). Only one SNP (CADM2; for exercising with others) was nominally significant $(p<0.05)$ before multiple testing correction. In the TwinsUK replication, we found directional consistency for 14 out of 25 SNPs, including 6 out of 8 overall PA-liking (GIP1) SNPs (Table 1). 
medRxiv preprint doi: https://doi.org/10.1101/2021.10.13.21264969; this version posted October 14, 2021. The copyright holder for this preprint (which was not certified by peer review) is the author/funder, who has granted medRxiv a license to display the preprint in perpetuity.

It is made available under a CC-BY-NC-ND 4.0 International license .

Genetic correlations

Genetic correlations among PA liking traits were moderate-to-strong (Figure 2). Among the PA

liking traits, strong correlations were observed for working up a sweat with going to the gym $\left(\mathrm{r}_{\mathrm{g}}=0.79\right)$,

exercising with others $\left(\mathrm{r}_{\mathrm{g}}=0.76\right)$, and exercising alone $\left(\mathrm{r}_{\mathrm{g}}=0.72\right)$, and the weakest correlation was a positive

one between exercising alone and exercising with others $\left(\mathrm{r}_{\mathrm{g}}=0.46\right)$. Across liking and behavior (self-reported

PA and accelerometer-derived PA) traits, correlations were strongest for PA-liking with self-reported

vigorous physical activity and strenuous sports and other exercise ( $r_{g}$ between 0.59 and 0.78$)$. Genetic

correlations of PA-liking with accelerometry traits were generally strongest for exercising alone $\left(\mathrm{r}_{\mathrm{g}} \approx 0.47\right)$,

and weakest with going to the gym $\left(\mathrm{r}_{\mathrm{g}} \approx 0.28\right)$. Genetic correlation assessments with a wide range of traits and

diseases reveal correlations with UK Biobank variables related to physical activity including accelerometry,

as well as with obesity-related traits, tiredness, and lifestyle traits such as alcohol consumption, TV

watching, and taking dietary supplements, among others (Figure 3).

PRSs of each PA-liking trait were calculated for each NTR participant, using as weights the effect

sizes resulting from the GWAS of the UK Biobank data. These PRSs were generally, but not always, most

strongly associated with the corresponding PA-liking phenotype (Supplementary Table 4). For example,

the exercising with others PRS was most strongly associated with exercising with others in NTR $\left(\mathrm{r}^{2}=0.79 \%\right.$,

$\left.\mathrm{p}=2.7 \times 10^{-13}\right)$. The overall PA-liking (GIP1) PRS was most strongly correlated with liking of exercising

alone $\left(\mathrm{r}^{2}=0.83 \%, \mathrm{p}=7.0 \times 10^{-15}\right.$; Supplementary Table 4). These PRSs were also significantly associated 
medRxiv preprint doi: https://doi.org/10.1101/2021.10.13.21264969; this version posted October 14, 2021. The copyright holder for this preprint (which was not certified by peer review) is the author/funder, who has granted medRxiv a license to display the preprint in perpetuity.

It is made available under a CC-BY-NC-ND 4.0 International license .

solitary exercise. Among the PA-liking PRSs, the best predictors of these self-reported PA phenotypes were going to the gym, and exercising with others in association with the self-reported PA measures of total exercise and solitary exercise (but not with team-based exercise; Supplementary Figure 1). When compared with the PRS based on the self-reported and accelerometer PA GWAS in UK Biobank, the liking PRSs had a similar predictive performance. For example, a PRS of self-reported SSOE (strenuous sports or other exercise) predicted self-report total exercise in NTR only slightly better than a PRS of liking going to the gym (Supplementary Figure 1). When the best predicting liking PRS (going to the gym) was combined with the best predicting self-reported PA PRS (SSOE), the prediction of self-reported PA in NTR improved from $r^{2}=0.42 \%$ to $r^{2}=0.59 \%$, corresponding to a $40 \%$ improvement in prediction, suggesting that these two measures are capturing distinct and complementary components of PA (Supplementary Figure 2).

\section{DISCUSSION}

With the advent of large-scale biobanks with genetic data, we are now able to identify genomic loci associated with complex behavioral and health-related traits such as PA. Here, we broaden and deepen our nascent understanding of the genetics of PA behavior by identifying genetic variants associated with PAliking. We found some but minimal overlap of loci with those identified for self-reported and accelerometer measures of PA, found genetic correlations with other health-related traits, including behaviors and health outcomes, and find that PRS of PA-liking adds substantially to prediction of PA in an independent sample, beyond a prediction based on a self-reported PA PRS.

$$
\text { SNP-based heritabilities of PA-liking traits (ranging from } 5.4 \text { to } 7.5 \% \text {; PA-liking (GIP1) }=8.9 \% \text { ) }
$$

were generally higher than those of self-reported behaviors at the baseline exam (ranging from 4.6 to $5.6 \%$ ), but lower than accelerometry measures $(14.3 \text { and } 11.0 \%)^{8}$, likely due to lower measurement error of 
medRxiv preprint doi: https://doi.org/10.1101/2021.10.13.21264969; this version posted October 14, 2021. The copyright holder for this preprint

accelerometry. Of all 24 loci identified for liking traits, only APOE, CADM2, HIST1H1D, and SKIDA1 were

significantly associated with self-reported or accelerometry-measured PA ${ }^{8,9}$. However, it is likely that some

of the other 20 loci are associated with PA behavior at a less stringent significance threshold. This relatively

small degree of overlap likely suggests that these measures of liking are reflecting different and specific

facets of PA, and attitudes and perceptions about PA, as opposed to PA behavior assessed by self-report or

accelerometry. It is possible that since accelerometers measure overall PA, and not just purposeful exercise,

the PA-liking traits are more strongly genetically correlated with self-reported PA than with accelerometer

measures of PA. On the other hand, the relatively low genetic correlation of going to the gym with

accelerometer-measured PA may reflect limitations of accelerometer measurements in the context of certain

types of PA such as resistance exercise. Genetic correlation analyses across a wider set of traits and diseases

mainly revealed correlations of PA-liking with self-reported PA and body fat measures. However, several

other notable findings such as negative genetic correlations with frequency of tiredness, fed-up feelings, and

alcohol intake frequency, and positive associations with usual walking pace, supplement intakes, and

variance in accelerometer measurements in UKB, were also observed. Some of these correlations may represent causal effects in one or both directions.

Among the individual loci identified, CADM2 has previously been identified in GWAS of BMI ${ }^{27}$,

risk taking and other behavioral traits ${ }^{28-30}$, including $\mathrm{PA}^{8}$. However, the pattern of association with $C A D M 2$

variants is particularly interesting since alleles associated with higher BMI are associated with higher levels

of PA and PA-liking, in the opposite direction of the phenotypic association. As the most consistently

identified genetic locus across self-reported PA and PA-liking measures, we will benefit from future work to understand the molecular mechanisms underlying this association. We found a SNP (rs7934107-T) in another cell adhesion molecule gene, CADM1, which was associated with working up a sweat. A SNP in the 
medRxiv preprint doi: https://doi.org/10.1101/2021.10.13.21264969; this version posted October 14, 2021. The copyright holder for this preprint

same gene was found to be associated with anorexia nervosa (SNP-risk allele: rs6589488-A) ${ }^{31}$. These alleles at these two SNPs are positively and moderately correlated $\left(\mathrm{r}^{2}=0.39\right)$.

Other identified loci share associations with several other traits such as social and emotional characteristics (e.g. MMS22L - KLHL32), lung function (e.g. POM12IL2 - PRSS16), food/drink intake (e.g. DARS1 - CENPL), and cognitive traits (e.g. MDK - CHRM4). However, our finding of an association of the $A P O E$ variant with exercising alone is likely the result of selection/survival bias due to older individuals with the $\varepsilon 4$ risk allele being relatively enriched for healthy behaviors that has offset their genetic risk, and enabled their survival and participation in the study ${ }^{8}$. It is possible that our estimates for other identified loci are subject to this bias, although it is likely to be minimal for nearly all genetic loci.

Although it turns out that we were under-powered to detect statistically significant associations in our replication cohorts, we did observe a nominally significant association of the CADM2 variant with liking of exercising with others in the NTR, further reinforcing this locus directly or indirectly in PA behavior, in addition to other traits, as mentioned above. In PRS analyses, we found that these PA-liking measures were genetically consistent across the UK Biobank and NTR samples, and that they could contribute substantially to the prediction and genetic understanding of (at least) self-reported PA behavior. It should be noted that the proportion of phenotypic variance explained by these PRS is still extremely small. This is at least partly attributable to the degree of measurement error one would expect from any self-report measure.

The strengths of this study include the relatively large sample size, the multiple measures of PAliking, the ability to examine correlations with both self-reported and accelerometry-derived PA behaviors, and the availability of two additional cohorts for replication and testing of PRS. The inclusion of middle-to-

247 older-age adults of European-descent individuals is a limitation of our study as these results may not generalize to other groups. 
medRxiv preprint doi: https://doi.org/10.1101/2021.10.13.21264969; this version posted October 14, 2021. The copyright holder for this preprint (which was not certified by peer review) is the author/funder, who has granted medRxiv a license to display the preprint in perpetuity.

It is made available under a CC-BY-NC-ND 4.0 International license .

In conclusion, we have identified genetic variants associated with PA-liking, further refining our

understanding of the genetics of PA behavior. Our results show that PA-liking can capture additional

elements of PA not captured by either self-report or accelerometry. Future work is needed to understand the

mechanisms linking the identified loci to PA behavior, and how these may vary over the life-course.

253 Examining the genetic correlates of stated liking for different facets of PA and how they associate with self-

reported and device-based measures of PA can provide insight into both the genetic and non-genetic

determinants of PA behavior, potentially help plan more effective interventions to improve PA habits, and

bridge gaps that may exist between liking and engaging in PA.

\section{ACKNOWLEDGMENTS}

This research was conducted using the UK Biobank Resource under Application Number 15678 and 19655. The authors would like to thank the funders, organizers and participants of the UK Biobank, the Netherlands Twin Register, and TwinsUK. J.F.W. acknowledges support from the MRC Human Genetics

Unit quinquennial programme grant "QTL in Health and Disease" (MC_UU_00007/10). TwinsUK receives

and European Union (H2020 contract \#733100). TwinsUK and M.M. are supported by the National Institute

for Health Research (NIHR)-funded BioResource, Clinical Research Facility and Biomedical Research

Centre based at Guy's and St Thomas' NHS Foundation Trust in partnership with King's College London.

C.M. is funded by the Chronic Disease Research Foundation and by the Medical Research Council

(MRC)/British Heart Foundation Ancestry and Biological Informative Markers for Stratification of

Hypertension (AIMHY; MR/M016560/1). G.E.A. acknowledges support from the National Institute on

Aging, NIH (AG072980, AG067200, AG064587), State of Arizona and Arizona Department of Health

271 Services, and McKnight Brain Research Foundation. Phenotyping in NTR was funded by BBRMI-CP2011- 
medRxiv preprint doi: https://doi.org/10.1101/2021.10.13.21264969; this version posted October 14, 2021. The copyright holder for this preprint (which was not certified by peer review) is the author/funder, who has granted medRxiv a license to display the preprint in perpetuity.

It is made available under a CC-BY-NC-ND 4.0 International license .

38: Enrichment of NTR with information on dietary intake and aspects of eating behavior (PI: Boomsma \&

273 Feskens); genotyping in NTR was funded by multiple grants from the Netherlands Organization for

274 Scientific Research (NWO) and The Netherlands Organisation for Health Research and Development

275 (ZonMW); the Biobanking and Biomolecular Resources Research Infrastructure (BBMRI -NL, 184.021.007

and 184.033.111), the European Community's Framework Programs (FP5- LIFE QUALITY-CT-2002-2006,

277 FP7- HEALTH-F4-2007-2013, grant 01254: GenomEUtwin, grant 01413: ENGAGE); the European

278 Research Council (ERC Starting 284167, ERC Consolidator 771057, ERC Advanced 230374), Rutgers

279 University Cell and DNA Repository (NIMH U24 MH068457-06), the National Institutes of Health (NIH,

280 R01D0042157-01A1, MH081802, DA018673, R01 DK092127-04, Grand Opportunity grant 1RC2

281 MH089951); and the Avera Institute for Human Genetics, Sioux Falls, South Dakota (USA).

282

\section{AUTHOR CONTRIBUTIONS}

Conceived and designed study: YCK \& NP. Performed data analyses: NP, YCK, AA, SMW, MN,

VB, MM, CM, MDVZ, JJH \& EJCdG. Drafting of manuscript: YCK \& NP. Critically revised the manuscript

for important intellectual content: YCK, NP, AA, SMW, MN, VB, MM, CM, DAR, GEA, MDVZ, JJH, JFW, EJCdG \& DIB.

\section{DATA AVAILABILITY}

Access to UK Biobank data is available to registered researchers upon application. GWAS summary statistics data for the UK Biobank PA-liking traits will be made available through the GWAS catalog portal at the time of publication. 
medRxiv preprint doi: https://doi.org/10.1101/2021.10.13.21264969; this version posted October 14, 2021. The copyright holder for this preprint (which was not certified by peer review) is the author/funder, who has granted medRxiv a license to display the preprint in perpetuity. It is made available under a CC-BY-NC-ND 4.0 International license .

\section{REFERENCES}

1. Lee, I.-M. et al. Effect of physical inactivity on major non-communicable diseases worldwide: an analysis of burden of disease and life expectancy. Lancet (London, England) 380, 219-229 (2012).

2. Blair, S. N. Physical inactivity: the biggest public health problem of the 21 st century. Br. J. Sports Med. 43, 1 LP - 2 (2009).

3. van der Ploeg, H. P., Chey, T., Korda, R. J., Banks, E. \& Bauman, A. Sitting Time and All-Cause Mortality Risk in 222497 Australian Adults. Archives of Internal Medicine vol. 172 494-500 (2012).

4. Stubbe, J. H. et al. Genetic influences on exercise participation in 37.051 twin pairs from seven countries. PLoS ONE vol. 1 (2006).

5. den Hoed, M. et al. Heritability of objectively assessed daily physical activity and sedentary behavior. The American journal of clinical nutrition vol. 98 1317-1325 (2013).

6. Franks, P. W. et al. Habitual physical activity in children: the role of genes and the environment. Am J Clin Nutr (2005).

7. Aaltonen, S., Ortega-Alonso, A., Kujala, U. M. \& Kaprio, J. A longitudinal study on genetic and environmental influences on leisure time physical activity in the Finnish Twin Cohort. Twin Res.

Hum. Genet. (2010) doi:10.1375/twin.13.5.475\r10.1375/twin.13.5.475 [pii].

8. Klimentidis, Y. C. et al. Genome-wide association study of habitual physical activity in over 377,000 UK Biobank participants identifies multiple variants including CADM2 and APOE. Int. J. Obes. 42, (2018).

9. Doherty, A. et al. GWAS identifies 14 loci for device-measured physical activity and sleep duration. Nat. Commun. 9, 5257 (2018).

10. Prince, S. A. et al. A comparison of direct versus self-report measures for assessing physical activity in adults: a systematic review. Int. J. Behav. Nutr. Phys. Act. 5, 56 (2008).

11. Sudlow, C. et al. UK Biobank: An Open Access Resource for Identifying the Causes of a Wide Range of Complex Diseases of Middle and Old Age. PLoS Med. 12, (2015).

12. Biobank, U. Food preferences web questionnaire. http://biobank.ctsu.ox.ac.uk/crystal/crystal/docs/foodpref.pdf (2020).

13. Bycroft, C. et al. The UK Biobank resource with deep phenotyping and genomic data. Nature 562, 203-209 (2018).

14. Ligthart, L. et al. The Netherlands Twin Register: Longitudinal Research Based on Twin and TwinFamily Designs. Twin Res. Hum. Genet. Off. J. Int. Soc. Twin Stud. 22, 623-636 (2019).

15. Vink, J. M., van Hooijdonk, K. J. M., Willemsen, G., Feskens, E. J. M. \& Boomsma, D. I. Causes of Variation in Food Preference in the Netherlands. Twin Res. Hum. Genet. Off. J. Int. Soc. Twin Stud. 23, 195-203 (2020).

16. Vilhjálmsson, B. J. et al. Modeling Linkage Disequilibrium Increases Accuracy of Polygenic Risk Scores. Am. J. Hum. Genet. 97, 576-592 (2015).

17. Verdi, S. et al. TwinsUK: The UK Adult Twin Registry Update. Twin Res. Hum. Genet. Off. J. Int. Soc. Twin Stud. 22, 523-529 (2019).

18. Pallister, T. et al. Food Preference Patterns in a UK Twin Cohort. Twin Res. Hum. Genet. Off. J. Int. Soc. Twin Stud. 18, 793-805 (2015).

19. Roederer, M. et al. The genetic architecture of the human immune system: a bioresource for autoimmunity and disease pathogenesis. Cell 161, 387-403 (2015).

20. Das, S. et al. Next-generation genotype imputation service and methods. Nat. Genet. 48, 1284-1287 (2016).

21. Jiang, L. et al. A resource-efficient tool for mixed model association analysis of large-scale data. Nat. 
Genet. 51, 1749-1755 (2019).

22. Bulik-Sullivan, B. K. et al. LD Score regression distinguishes confounding from polygenicity in genome-wide association studies. Nat Genet 47, 291-295 (2015).

23. Tsepilov, Y. A. et al. Analysis of genetically independent phenotypes identifies shared genetic factors associated with chronic musculoskeletal pain conditions. Commun. Biol. 3, 329 (2020).

24. Timmers, P. R. H. J., Wilson, J. F., Joshi, P. K. \& Deelen, J. Multivariate genomic scan implicates novel loci and haem metabolism in human ageing. Nat. Commun. 11, 3570 (2020).

25. Zheng, J. et al. LD Hub: a centralized database and web interface to perform LD score regression that maximizes the potential of summary level GWAS data for SNP heritability and genetic correlation analysis. Bioinformatics 33, 272 (2017).

26. Finucane, H. K. et al. Partitioning heritability by functional annotation using genome-wide association summary statistics. Nat. Genet. 47, 1228-1235 (2015).

27. Speliotes, E. K. et al. Association analyses of 249,796 individuals reveal 18 new loci associated with body mass index. Nat Genet 42, 937-948 (2010).

28. Boutwell, B. et al. Replication and characterization of CADM2 and MSRA genes on human behavior. Heliyon 3, e00349 (2017).

29. Day, F. R. et al. Physical and neurobehavioral determinants of reproductive onset and success. Nat Genet 48, 617-623 (2016).

30. Strawbridge, R. J. et al. Genome-wide analysis of self-reported risk-taking behaviour and crossdisorder genetic correlations in the UK Biobank cohort. Transl. Psychiatry 8, 39 (2018).

31. Watson, H. J. et al. Genome-wide association study identifies eight risk loci and implicates metabopsychiatric origins for anorexia nervosa. Nat. Genet. 51, 1207-1214 (2019). 

in UKB, with replication results from NTR and Twins UK.

\begin{tabular}{|c|c|c|c|c|c|c|c|c|c|c|c|c|c|c|c|c|c|c|}
\hline \multicolumn{11}{|c|}{ UK Biobank } & \multicolumn{4}{|c|}{ NTR replication } & \multicolumn{4}{|c|}{ Twins UK replication } \\
\hline SNP & Chr & Position & Nearest gene(s) & $\begin{array}{l}\text { Effect } \\
\text { allele }\end{array}$ & $\begin{array}{l}\text { Other } \\
\text { allele }\end{array}$ & EAF & Beta & SE & p-value & $\mathbf{n}$ & Beta & SE & $\begin{array}{c}\text { p- } \\
\text { value }\end{array}$ & $\mathbf{n}$ & Beta & SE & $\begin{array}{c}\text { p- } \\
\text { value }\end{array}$ & $\mathbf{n}$ \\
\hline \multicolumn{19}{|l|}{ Going to gym } \\
\hline rs17370393 & 1 & $190,526,252$ & BRINP3 & $\mathrm{T}$ & $\mathrm{C}$ & 0.15 & 0.010 & 0.002 & $3.80 \mathrm{E}-09$ & 140,015 & 0.002 & 0.007 & 0.749 & 7,371 & -0.007 & 0.015 & 0.623 & 1,366 \\
\hline rs61882686 & 11 & $46,390,680$ & MDK, CHRM4 & A & $\mathrm{C}$ & 0.09 & 0.013 & 0.002 & $5.90 \mathrm{E}-09$ & 140,015 & -0.002 & 0.009 & 0.869 & 7,371 & 0.014 & 0.020 & 0.461 & 1,366 \\
\hline \multicolumn{19}{|c|}{ Working up a sweat } \\
\hline rs4645151 & 3 & $18,730,433$ & SATB1, TBCID5 & $\mathrm{T}$ & $\mathrm{C}$ & 0.69 & -0.006 & 0.001 & $8.90 \mathrm{E}-09$ & 158,189 & $-0.008^{\mathrm{a}}$ & 0.004 & 0.057 & 7,874 & 0.001 & 0.011 & 0.898 & 1,471 \\
\hline rs112403434 & 7 & $114,528,614$ & MDFIC & A & G & 0.06 & -0.013 & 0.002 & $7.50 \mathrm{E}-10$ & 158,189 & -0.001 & 0.008 & 0.888 & 7,874 & 0.033 & 0.022 & 0.135 & 1,471 \\
\hline rs7934107 & 11 & $115,144,046$ & $C A D M 1$ & $\mathrm{~T}$ & $\mathrm{C}$ & 0.1 & 0.009 & 0.002 & $2.30 \mathrm{E}-08$ & 158,189 & 0.001 & 0.006 & 0.918 & 7,874 & 0.023 & 0.015 & 0.138 & 1,471 \\
\hline \multicolumn{19}{|c|}{ Exercising with others } \\
\hline rs 25571 & 1 & $173,773,928$ & DARSI, CENPL & CTT & $\mathrm{C}$ & 0.53 & 0.006 & 0.001 & $4.40 \mathrm{E}-08$ & 153,358 & $0.004^{\mathrm{b}}$ & 0.004 & 0.383 & 7,738 & -0.001 & 0.009 & 0.883 & 1,456 \\
\hline rs 4672114 & 2 & $56,614,299$ & CCDC85A, EFEMPI & $\mathrm{C}$ & G & 0.3 & -0.007 & 0.001 & $2.40 \mathrm{E}-08$ & 153,358 & -0.007 & 0.005 & 0.129 & 7,738 & -0.003 & 0.010 & 0.740 & 1,456 \\
\hline rs13096057 & 3 & $85,342,567$ & CADM2 & A & $\mathrm{C}$ & 0.61 & 0.007 & 0.001 & $2.60 \mathrm{E}-09$ & 153,358 & $0.009^{c}$ & 0.004 & 0.048 & 7,738 & $0.010^{\mathrm{j}}$ & 0.010 & 0.323 & 1,456 \\
\hline rs113176495 & 11 & $46,789,346$ & $F 2$, ZNF408 & GT & G & 0.09 & 0.010 & 0.002 & $4.50 \mathrm{E}-08$ & 153,358 & $0.006^{\mathrm{d}}$ & 0.008 & 0.470 & 7,738 & 3.3E-04 & 0.017 & 0.985 & 1,456 \\
\hline rs9584870 & 13 & $99,245,866$ & STK24, FARPI-ASI & $\mathrm{C}$ & $\mathrm{T}$ & 0.37 & 0.007 & 0.001 & $7.30 \mathrm{E}-09$ & 153,358 & 0.005 & 0.005 & 0.302 & 7,738 & 0.022 & 0.010 & 0.026 & 1,456 \\
\hline rs169407 & 22 & $41,935,063$ & POLR3H, CSDC2 & A & G & 0.36 & 0.006 & 0.001 & $1.40 \mathrm{E}-08$ & 153,358 & -0.002 & 0.005 & 0.590 & 7,738 & -0.018 & 0.010 & 0.063 & 1,456 \\
\hline \multicolumn{19}{|c|}{ Exercising alone } \\
\hline rs10875127 & 1 & $98,527,414$ & $D P Y D$ & G & A & 0.31 & 0.006 & 0.001 & $9.50 \mathrm{E}-09$ & 156,371 & -0.002 & 0.005 & 0.761 & 7,703 & -0.001 & 0.011 & 0.928 & 1,454 \\
\hline rs149896934 & 6 & $26,230,172$ & HISTIHID, HISTIH3E & AAAAT & A & 0.18 & -0.008 & 0.001 & $6.80 \mathrm{E}-09$ & 156,371 & $-0.010^{\mathrm{e}}$ & 0.006 & 0.133 & 7,703 & -0.016 & 0.014 & 0.252 & 1,454 \\
\hline rs11275375 & 10 & $21,839,820$ & SKIDA1, MLLTIO & insertion ${ }^{*}$ & $\mathrm{~T}$ & 0.32 & -0.007 & 0.001 & $4.50 \mathrm{E}-12$ & 156,371 & $-0.004^{f}$ & 0.005 & 0.413 & 7,703 & 0.011 & 0.010 & 0.287 & 1,454 \\
\hline rs429358 & 19 & $45,411,941$ & APOE, APOCI & C & $\mathrm{T}$ & 0.15 & 0.009 & 0.001 & $1.90 \mathrm{E}-09$ & 156,371 & 0.001 & 0.006 & 0.868 & 7,703 & 0.009 & 0.014 & 0.485 & 1,454 \\
\hline \multicolumn{19}{|l|}{ Bicycling } \\
\hline rs5850689 & 3 & $85,586,903$ & CADM2 & $\mathrm{T}$ & TG & 0.63 & -0.008 & 0.001 & $1.00 \mathrm{E}-10$ & 148,803 & $-0.004^{\mathrm{g}}$ & 0.003 & 0.188 & 7,936 & $-5.0 \mathrm{E}-04^{\mathrm{k}}$ & 0.011 & 0.965 & 1,424 \\
\hline rs 16897515 & 6 & $27,278,020$ & POM12IL2, PRSS16 & $\mathrm{C}$ & A & 0.19 & -0.008 & 0.001 & $3.20 \mathrm{E}-08$ & 148,803 & 0.001 & 0.004 & 0.886 & 7,936 & 0.014 & 0.014 & 0.303 & 1,424 \\
\hline \multicolumn{19}{|c|}{ PA-liking (GIPI) } \\
\hline rs17370393 & 1 & $190,526,252$ & BRINP3 & $\mathrm{T}$ & $\mathrm{C}$ & 0.15 & 0.028 & 0.005 & $2.12 \mathrm{E}-08$ & 151,347 & -0.007 & 0.022 & 0.754 & 7,724 & -0.069 & 0.051 & 0.176 & 1,434 \\
\hline rs7616022 & 3 & $85,086,321$ & CADM2 & $\mathrm{C}$ & $\mathrm{T}$ & 0.89 & 0.040 & 0.006 & $3.50 \mathrm{E}-11$ & 151,347 & $0.008^{\mathrm{h}}$ & 0.016 & 0.599 & 7,724 & 0.032 & 0.037 & 0.392 & 1,434 \\
\hline rs9379831 & 6 & $26,175,852$ & HISTIH2BE, HISTIH4D & A & $\mathrm{C}$ & 0.31 & 0.023 & 0.004 & $3.55 \mathrm{E}-09$ & 151,347 & 0.013 & 0.017 & 0.457 & 7,724 & 0.094 & 0.040 & 0.020 & 1,434 \\
\hline rs 2263321 & 6 & $31,340,908$ & $H L A-B, M I C A$ & A & G & 0.33 & -0.022 & 0.004 & $7.00 \mathrm{E}-09$ & 151,347 & -0.006 & 0.017 & 0.706 & 7,724 & -0.015 & 0.040 & 0.708 & 1,434 \\
\hline rs9374462 & 6 & $97,725,028$ & $M M S 22 L, K L H L 32$ & $\mathrm{~T}$ & $\mathrm{C}$ & 0.19 & 0.029 & 0.005 & $4.45 \mathrm{E}-10$ & 151,347 & 0.011 & 0.022 & 0.621 & 7,724 & 0.032 & 0.047 & 0.489 & 1,434 \\
\hline rs11012749 & 10 & $21,892,488$ & SKIDA1, MLLT10 & $\mathrm{C}$ & A & 0.53 & -0.021 & 0.004 & $6.04 \mathrm{E}-09$ & 151,347 & 0.012 & 0.016 & 0.460 & 7,724 & -0.030 & 0.038 & 0.418 & 1,434 \\
\hline rs3993050 & 11 & $22,548,634$ & GAS2, FANCF & $\mathrm{C}$ & A & 0.68 & 0.022 & 0.004 & 4.13E-08 & 151,347 & $0.029^{\mathrm{i}}$ & 0.030 & 0.336 & 7,724 & $0.050^{1}$ & 0.042 & 0.237 & 1,434 \\
\hline rs4468472 & 13 & $111,528,251$ & ANKRD10, CARS2 & $\mathrm{C}$ & $\mathrm{T}$ & 0.41 & -0.022 & 0.004 & $6.14 \mathrm{E}-09$ & 151,347 & -0.026 & 0.016 & 0.106 & 7,724 & 0.001 & 0.038 & 0.976 & 1,434 \\
\hline
\end{tabular}

The beta coefficient units refer to the units used in the scale, from 1 to 9. EAF: effect allele frequency; SE: standard error; $n=$ sample size used in analysis; SNP position based on GRCh37

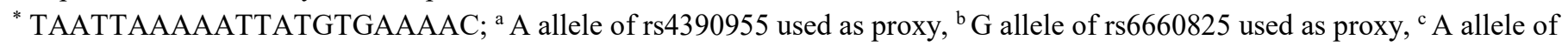
rs7642661 used as proxy, ${ }^{\mathrm{d}} \mathrm{C}$ allele of rs3136434 used as proxy, ${ }^{\mathrm{e}} \mathrm{A}$ allele of rs1417998 used as proxy, ${ }^{\mathrm{f}} \mathrm{G}$ allele of rs 1802669 used as proxy, ${ }^{\mathrm{g}} \mathrm{A}$ allele of rs 2167046 used as proxy, ${ }^{\mathrm{h}} \mathrm{C}$ allele of rs 76508707 used as proxy, ${ }^{\mathrm{i}} \mathrm{A}$ allele of rs 3136469 used as proxy, ${ }^{\mathrm{j}} \mathrm{G}$ allele of rs2326128 used as proxy, ${ }^{\mathrm{k}} \mathrm{G}$ allele of rs12494446 used as proxy, ${ }^{1} \mathrm{G}$ allele of rs7120717 used as proxy. 
medRxiv preprint doi: https://doi.org/10.1101/2021.10.13.21264969; this version posted October 14, 2021. The copyright holder for this preprint (which was not certified by peer review) is the author/funder, who has granted medRxiv a license to display the preprint in perpetuity.

It is made available under a CC-BY-NC-ND 4.0 International license .

Figure 1: Manhattan plots of five physical activity liking traits and overall PA-liking (GIP1).
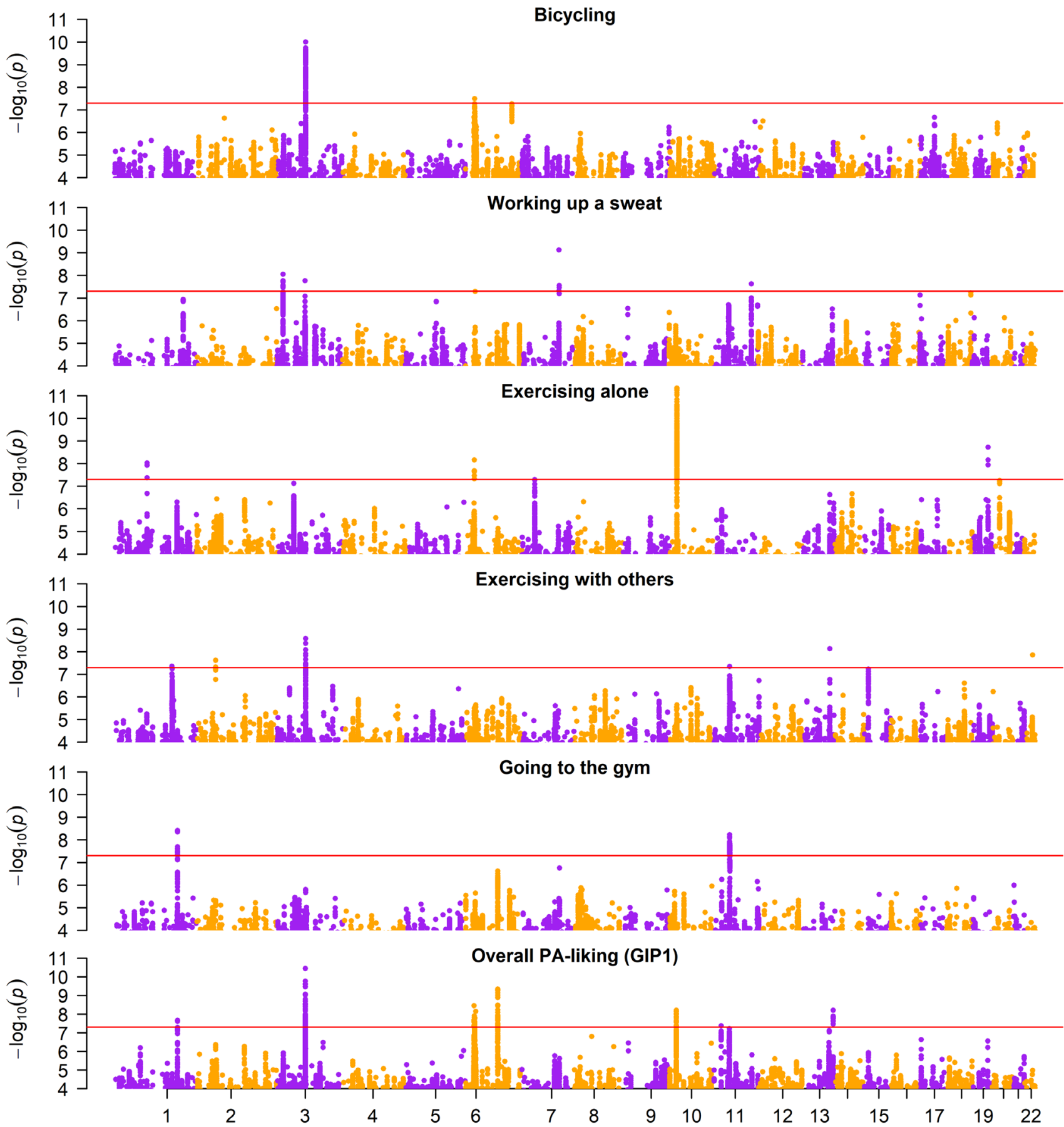
medRxiv preprint doi: https://doi.org/10.1101/2021.10.13.21264969; this version posted October 14, 2021. The copyright holder for this preprint (which was not certified by peer review) is the author/funder, who has granted medRxiv a license to display the preprint in perpetuity.

It is made available under a CC-BY-NC-ND 4.0 International license .

370 Figure 2: Genetic correlations across PA self-report, PA from accelerometry, and PA-liking traits.

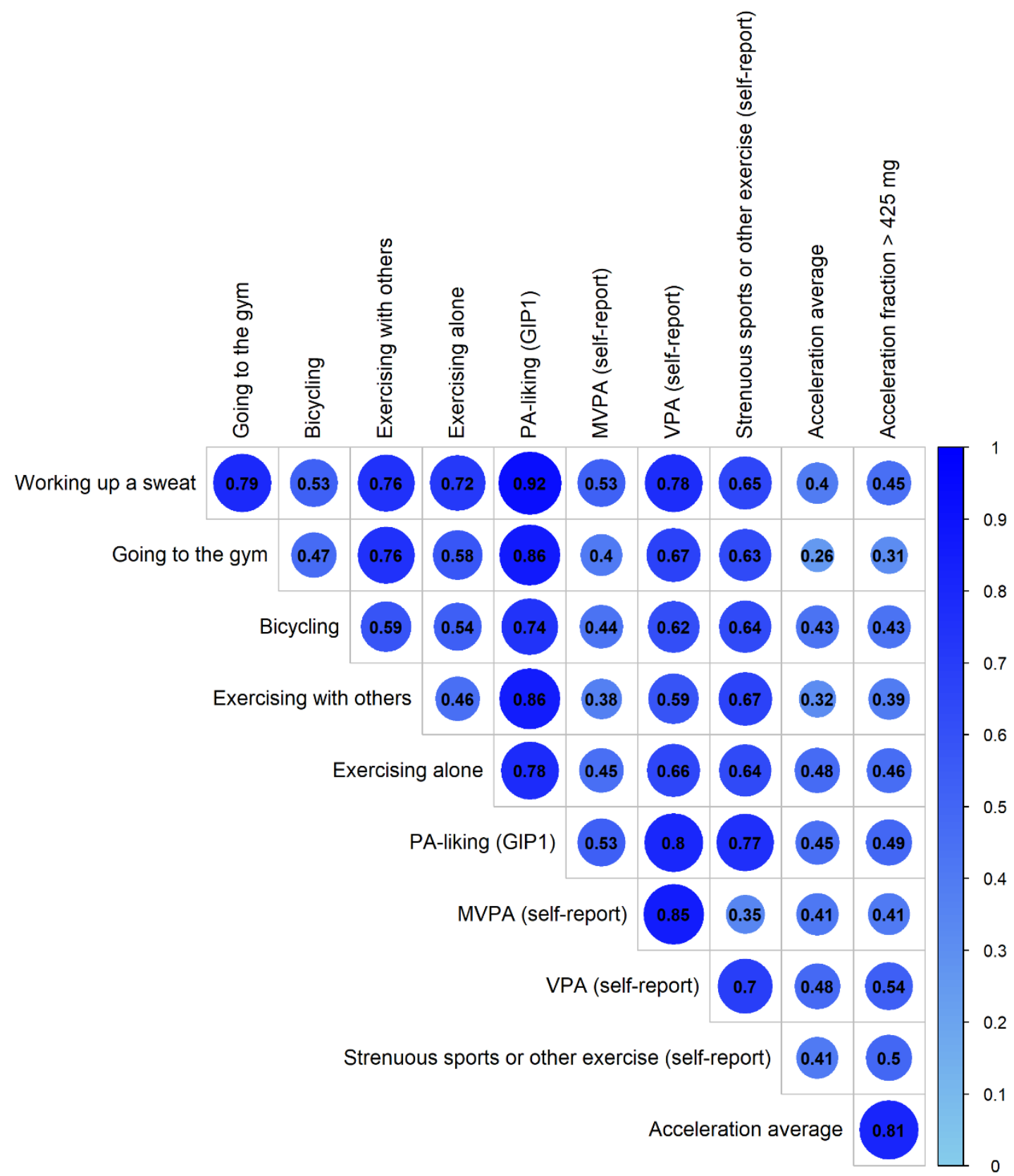


medRxiv preprint doi: https://doi.org/10.1101/2021.10.13.21264969; this version posted October 14, 2021. The copyright holder for this preprint (which was not certified by peer review) is the author/funder, who has granted medRxiv a license to display the preprint in perpetuity.

It is made available under a CC-BY-NC-ND 4.0 International license.

372 Figure 3: Genetic correlations of PA-liking traits with other traits and diseases. Top ten correlations are shown according to p-value. The order of traits shown in each panel is in ascending order by p-value. Error bars represent $95 \%$ CI.
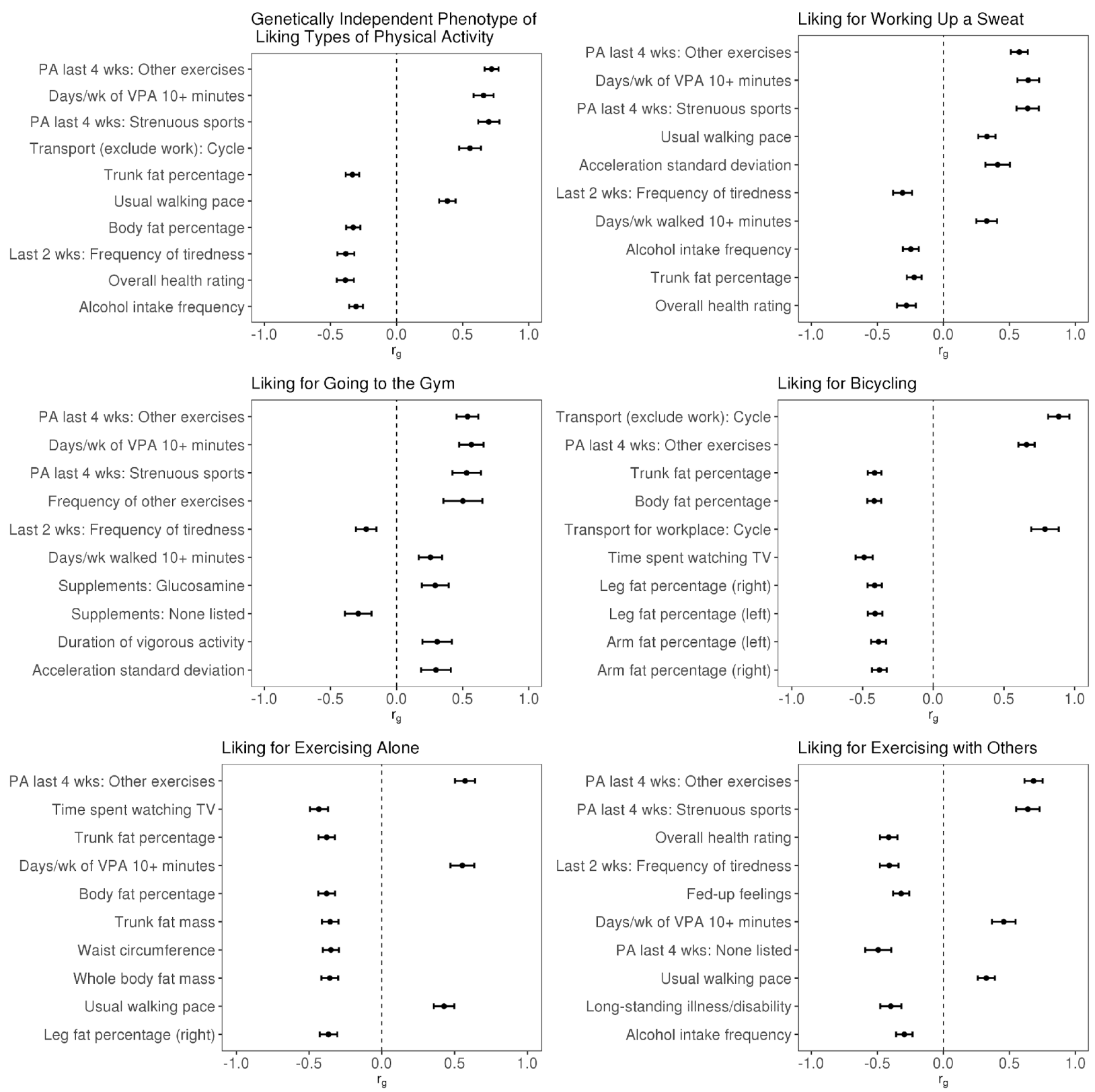